\title{
a \\ Ultrasound, computed tomography and surgical observations in the evaluation and staging of the renal cell carcinoma
}

\author{
DOI:_ https://doi.org/10.32007/med.1936/jfacmedbagdad.v60i3.5
}

(4) (9)

This work is licensed under a Creative Commons Attribution-NonCommercial 4.0 International License.

\author{
Khaleel I. Mohson* \\ Hana A. Ali**
}

\author{
DMRD, CABMS (radiology) \\ DMRD (radiology)
}

\section{Abstract}

Background: The evaluation and staging of renal cell carcinoma (RCC) has dramatically changed with the introduction of cross-sectional imaging. Nowadays, small renal lesions are easily detected by computed tomography (CT) examination while missed by other modalities.

Objective: To determine whether ultrasound (US) or CT scan is the optimum imaging modality for the

J Fac Med Baghdad

2018; Vol.60, No.3

Received: Oct., 2018

Accepted: Dec., 2018

Published: Dec.2018

evaluation of the renal masses.

Patients and methods: This is a comparative study in which 30 patients with hematuria were attending the urological consulting clinic in Ghazzi Al-Harriry hospital, Baghdad, Iraq from May 2016 to July 2017 were subjected to abdominal US and CT scan.

Results: The patients included in the study were 19 females and 11 males. The results of US, unenhanced and contrast CT for characterization of the consistency of renal mass were $63.4 \%, 56.7 \%$, and $60 \%$ respectively for the solid, while the cystic were $23.3 \%, 23.3 \%$, and $26.6 \%$ and for complex was $13.3 \%, 20 \%$ and $13.4 \%$ respectively. The size of the masses was compatible in $60 \%$ of cases. Mass surface regularity was compatible in $93.4 \%$.

Regarding mass position, the US showed that $96.7 \%$ to be confined to the kidney and $4.3 \%$ extended outside, while $66.6 \%$ were judged to be confined by CT scan, which is nearly similar to the operative findings which revealed $60 \%$ localized masses to kidney and $40 \%$ extending outside the kidney.

Conclusion: the US is a good modality to start with in the assessment of renal lesions, but CT scan is still the main tool to diagnose and stage RCC.

Keywords: computed tomography, abdominal ultrasound, renal mass, renal cell carcinoma.

\section{Introduction:}

Renal masses, especially renal cell carcinomas

(RCC) are the most common cancer affecting the kidney. Early detection before local, lymphatic and venous invasion takes place is critical for the management and subsequent survival. The early detection of the tumor especially when small is easily achieved by cross-sectional imaging namely the CT scan, which also performs preoperative staging $(1,2,3)$. Ultrasound, in general, is a simple, fast, available, lacking ionizing radiation and a costeffective technique (4). Ultrasound can easily detect renal masses and categorize them to solid, cystic, or complex (5). The use of color Doppler is an additive to the efficiency of ultrasound by characterizing the neovascularity of the lesion and assessing its waveform (6). The Drawback of ultrasound, in general, is being operator dependent and subjected to inter-observer variations (7). While detecting the renal mass, it is poor in the detection of extrarenal tissue invasion and in assessing venous extension of RCC especially to distal renal vein and infrahepatic portion of the inferior vena cava (IVC). While 100\% sensitive in detecting intrahepatic or suprahepatic venous thrombosis (8),

*Head of clinical department, national cancer research center, University of Baghdad. Email: khalelcabms@gmail.com

**Specialist radiologist, Bakooba hospital, Diala. dr_sabaqais@yahoo.com overall still inferior to $\mathrm{CT}$ and magnetic resonance imaging in the staging of hypernephroma (9). CT scan became the modality of choice in the assessment of renal tumors, especially when it incidentally detects RCC in patients complaining of flank pain and hematuria (10). CT examination is usually performed unenhanced (without venous contrast), then after intravenous (IV) contrast injection in the corticomedullary phase and nephrographic phase with a delay of 40 seconds and 75-85 seconds respectively. In the corticomedullary phase the contrast enters the renal capillaries and infiltrates the peritubular interstitium and then passes to the cortical tubules, so it usually used to assess renal vascularity, renal artery stenosis, aneurysm, arteriovenous malformation and tumor extension to the renal vein. The nephrographic phase is best for differentiating between renal medulla and renal mass. The excretory phase is usually used for the evaluation of transitional cell carcinoma or urothelial origin, where renal cell carcinoma is usually hypodense in comparison with renal parenchyma and shows enhancement $>20$ Hounsfield (HU) to unenhanced scan, highlighted in corticomedullary phase and of less enhancement than surrounding renal tissue on nephrographic phase $(11,12)$. 


\section{Patients and Methods:}

This is a comparative study conducted in the period between 25/5/2016 to 20/7/2017 and included thirty patients who were referred to the radiological department from the urological consulting clinic in Martyr Gazzi Al-Harriry Hospital/ Medical City Complex/ Baghdad/ Iraq for abdominal US and CT scan to evaluate them for the presenting symptom, hematuria, from whom only patients with renal masses by ultrasound were included in the study and subsequently underwent CT exam. Patient's data were recorded and included the name, age, gender and the findings of US and the CT scan of the abdomen (unenhanced and contrast) which includes the mass size, component (whether cystic or solid) and the extension of the mass outside the kidney. The US examination was performed using (PHILIPS HD $11 \mathrm{XE}$ ) machine with the patient supine and the abdomen exposed from the epigastric area to suprapubic area. The examination lasts for from 20 - 25 minutes during which the patient is examined in supine, then right anterior oblique (RAO) and left anterior oblique (LAO) positions for kidney assessment. These positions are used to reveal the full longitudinal and transverse axes of both kidneys. The right kidney is sometimes scanned through the liver and posteriorly in the right loin. The left kidney is visualized from the lateral approach. In difficult cases the patient lies on the side with a pillow under the left loin and asked to take a deep breath for better visualization. The variable recorded are: Mass size, outline, position, component, probable capsular invasion, renal hilar lymphadenopathy, general lymphadenopathy, renal vessels, and the state of the contralateral kidney. The CT scan of the abdomen is performed using (SIEMENS, SOMATOM AS, Erlangen, Germany). For each patient, venous access was obtained, then the patient lies supine, after that scanogram of chest, abdomen, and pelvis is obtained, then an unenhanced scans of the abdomen is undertaken. Finally, post intravenous contrast scan is performed using low osmolar contrast material (iohexol Omnipaque) $300 \mathrm{mg} / \mathrm{ml}$. About $100 \mathrm{ml}$ is given as bolus IV are obtained through the kidneys in order to assess pre-contrast attenuation and subsequent post-contrast enhancement patterns can be performed after 70 seconds of contrast injection. The parameters recorded include: Mass size, outline, position, component, capsular invasion, degree of enhancement, hilum lymph nodes, general lymph nodes, renal vessels invasion, and contralateral kidney assessment. Postoperatively, the operative notes and histopathological results were recorded and correlated with the corresponding ultrasound and CT findings.

\section{Statistical analysis:}

All patients' data were entered into computerized statistical software; Statistical Package for Social Sciences (SPSS) version 20 was used. Descriptive statistics were presented as numbers and percentages. Multiple contingency tables were constructed and appropriate statistical tests performed. The Fishers exact test was used for testing associations of categorical variables.

\section{Results:}

Figure (1) shows that out of the 30 patients included in the study, 19 were females $(63.3 \%)$ and the 11 were males (36.7\%). Figure (2) shows the age distribution of the cases, with the highest frequency being in the 41-50 years group (40\%) followed by $51-60$ years group $(23.3 \%)$.

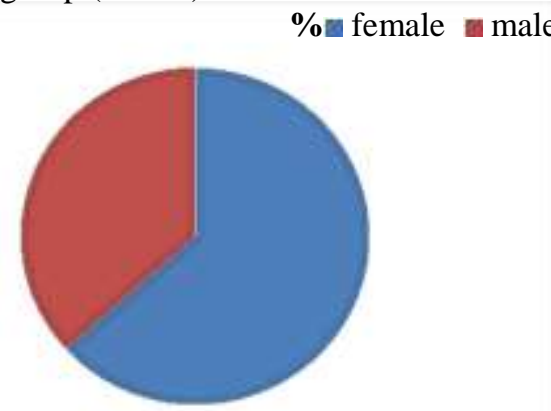

Figure (1): Gender distribution of the patients

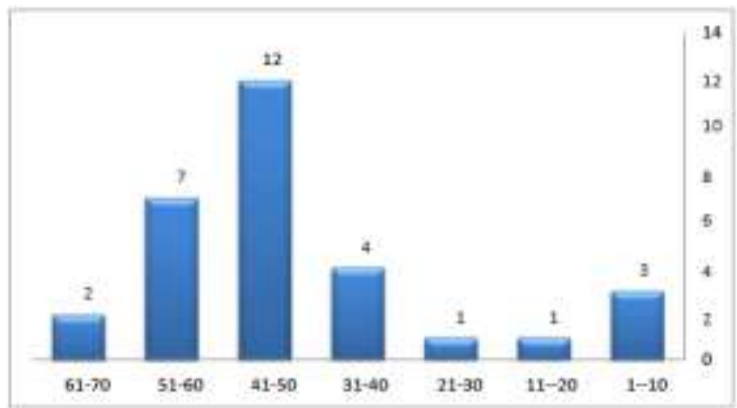

Figure (2): Age distribution of the patients

The consistency of the masses in US examination was found to be solid in 19 cases $(63.3 \%)$, cystic in $7(23.3 \%)$ and complex in 4 patients $(13.3 \%)$, while the results of the unenhanced CT scan showed them to be solid in 17 cases (56.7\%), cystic in 7 (23.3\%) and complex in 6 cases $(20 \%)$ with no significant difference of the results between US, unenhanced and contrast CT scan regarding the solid and cystic masses. However, a significant difference was found in the detection of complex masses with $(\mathrm{P}<0.05)-$ table (1). Comparing the results of contrast CT scan with unenhanced CT scan, the former showed that the mass being solid in $18(60 \%)$, cystic in 8 (26.6\%) and complex in $4(13.4 \%)$ - figure (3), with no significant difference regarding the cystic, and significant differences regarding the solid and complex masses $(\mathrm{P}<0.05)$.

Table (1): Comparison of the consistency of the mass between ultrasound, unenhanced \& contrast CT scan examinations

\begin{tabular}{lllllll}
\hline \multirow{2}{*}{$\begin{array}{l}\text { Consistency } \\
\text { the mass }\end{array}$} & \multicolumn{2}{l}{ of Ultrasound } & \multicolumn{2}{l}{$\begin{array}{l}\text { Unenhanced } \\
\text { scan }\end{array}$} & $\begin{array}{l}\text { CTContrast } \\
\text { scan }\end{array}$ & CT \\
\cline { 2 - 8 } & No & $\%$ & No. & $\%$ & No. & $\%$ \\
\hline Solid & 19 & 63.4 & 17 & 56.7 & 18 & 60 \\
\hline Cystic & 7 & 23.3 & 7 & 23.3 & 8 & 26.6 \\
\hline Complex & 4 & 13.3 & 6 & 20 & 4 & 13.4 \\
\hline Total & 30 & 100 & 30 & 100 & 30 & 100 \\
\hline
\end{tabular}


The results of US and CT scan examinations regarding the assessment of the size of the mass which was categorized according to AJCC TNM staging system (small $<4 \mathrm{~cm}$, moderate $4-7 \mathrm{~cm}$ and large $>7 \mathrm{~cm})$ were compatible in 18 cases $(60 \%)$ and incompatible in other $12(40 \%)$ of patients with a significant difference P-value at 0.05 (Table 2).

Table (2): Compatibility of the results between the Ultrasound and the $\mathrm{CT}$ scan regarding the size of the mass.

\begin{tabular}{lllll}
\hline & \multicolumn{2}{l}{ Compatible } & \multicolumn{2}{l}{ Incompatible } \\
\cline { 2 - 5 } Size of the mass & No & $\%$ & No. & $\%$ \\
\hline Small $<4 \mathrm{~cm}$ & 10 & 33.5 & 4 & 13.4 \\
\hline Medium $4-7 \mathrm{~cm}$ & 6 & 19.8 & 7 & 13.3 \\
\hline Large $>7 \mathrm{~cm}$ & 2 & 6.7 & 4 & 13.3 \\
\hline Total & 18 & 60 & 12 & 40 \\
\hline
\end{tabular}

Considering the description of mass margin regularity the US and the CT scan results were compatible in $28(93.4 \%)$ cases and incompatible in $2(6.6 \%)$ cases with no significant difference pvalue $>0.05$, table (3)

Table (3): Compatibility of the results between the Ultrasound and the $\mathrm{CT}$ scan regarding the outline of the mass surface.

\begin{tabular}{lllll} 
& \multicolumn{2}{l}{ Compatible } & \multicolumn{2}{l}{ Incompatible } \\
\cline { 2 - 5 } Outline the mass & No & $\%$ & No. & $\%$ \\
\hline Regular & 19 & 63.4 & 1 & 3.3 \\
\hline Irregular & 9 & 30.0 & 1 & 3.3 \\
\hline Total & 28 & 93.4 & 2 & 6.6
\end{tabular}

The comparative results between the US and the unenhanced CT scan describing the relation of the mass to the kidney outline, the confined tumor defined as lesion limited to renal capsule which appears clear. The lesion was considered outside the kidney when in contact with nearby adrenal or results in perinephric fatty standing. The mass was localized to the kidney in $29(96.7 \%)$ of the cases, while extrarenal extension was detected in one case $(4.3 \%)$ by US. The outcome of the unenhanced CT scan decreases the limitation of the mass to kidney to $20(66.6 \%)$ cases and increases the extrarenal invasion to $10(33.4 \%)$. Comparing the results of the unenhanced CT scan with the results of the contrast CT scan regarding the assessment of mass position showed that the mass was restricted to the kidney in $19(63.4 \%)$ patients, while in $11(36.6 \%)$ patients the mass extended outside the kidney, with no significant difference with unenhanced $\operatorname{scan}(\mathrm{P}>$ 0.05 , Table (4).

Table (4): Comparative result between the ultrasound, unenhanced \& contrast CT scan examination regarding the position of the mass.

\begin{tabular}{lllllll}
\hline \multirow{2}{*}{ Site of the mass } & \multicolumn{2}{l}{ Ultrasound } & \multicolumn{3}{c}{ Unenhanced Contrast } \\
\cline { 2 - 7 } & No & $\%$ & No.T scan & $\%$ & \multicolumn{2}{l}{ C.T scan } \\
\hline Localized to the kidney & 29 & 96.7 & 20 & 66.6 & 19 & 63.4 \\
\hline Outside the kidney & 1 & 4.3 & 10 & 33.4 & 11 & 36.6 \\
\hline Total & 30 & 100 & 30 & 100 & 30 & 100 \\
\hline
\end{tabular}

Comparing the above results with operative findings there is no significant difference considering the localization of the mass in relation to the kidney for unenhanced and contrast-enhanced $\mathrm{CT}$ scan (P $>0.05$ ) while there was a significance difference for US findings ( $\mathrm{P}<0.05$, Table (5).

Table (5): Descriptive results according to modality imaging and operative findings regarding the position of the mass.

\begin{tabular}{llllll}
\multirow{2}{*}{\begin{tabular}{l} 
Type of Imaging modality $\begin{array}{l}\text { Localized } \\
\text { the kidney }\end{array}$ \\
\cline { 2 - 5 }
\end{tabular}} & \multicolumn{3}{c}{$\begin{array}{l}\text { Extending } \\
\text { to outside } \\
\text { kidney }\end{array}$} \\
\hline Ultrasound & $\%$ & No. & $\%$ \\
Unenhanced CT scan & 29 & 96.7 & 1 & 4.3 & 30 \\
\hline Contrast CT scan & 19 & 63.4 & 11 & 36.6 & 30 \\
\hline Operative findings & 18 & 60 & 12 & 40 & 30 \\
\hline
\end{tabular}

\section{Discussion:}

The revolution in US software and the introduction of multidetector CT scanners improved the detection and characterization of incidental and symptomatic patients with probable renal masses (13). In our study series, there was a female predominance over the males (63.3\% vs $36.7 \%$ respectively), in contrast to the results of Mike et al which showed male predominance over females $(63 \%$ vs $37 \%$ respectively). This may be explained environmental, life-style and racial differences (14). The highest number of cases in our study was between 41-50 years, whereas the results of Karakiewicz et al showed that the highest frequency was seen over 50 years (15). In this study the outcome of US and CT scan results for assessment of the mass consistency showed that no remarkable difference even with enhanced technique and likewise regarding the description of mass margin which showed a high compatibility of the results between the US and CT scan to characterize the regularity of the mass which endorses the role and efficiency of US for evaluation of these parameters in comparison with CT scan. The accuracy of US is comparable with CT scan for larger masses, but less so for smaller lesions, which is probably related to body habits of the patients and their cooperation. A recognizable difference between the results of US and CT examination is noted in the description of the extension of the mass outside the kidney, where the US showed masses to be confined to the kidney in $96.7 \%$ of patients, while the CT scan showed that $66.6 \%$ of the masses were completely within the kidney. This is supported by the operative findings, indicating that CT scan is more reliable in staging renal carcinomas. The difference between the two modalities is due to poor tissue contrast difference between the masses and the perinephric fat and the limited field of view depicted by ultrasound. In our study, the characterization of the mass size in contrast to CT size showed that $53.1 \%$ more than 4 $\mathrm{cm}$ and $46.8 \%$ less than $4 \mathrm{~cm}$ which is not highly different from the study done by Nazim et al which showed that the mean size of the tumor is $7.5 \mathrm{~cm}$ (16). In a study done by Golberg et al, the US 
and staging of the renal cell carcinoma

results for characterization of the renal mass were solid $25.3 \%$, cystic $61.3 \%$ and complex $13.4 \%$, very close to the results in our study. Another study for evaluation of renal mass size done by Jamis-Dow et al shows $64 \%$ compatibility between the US and CT scan examination which is slightly higher than the results in our study (table 2), with the sample size being nearly the same in both studies. This may be explananed by the multiplanar capability of the CT scan and increasing the contrast difference between the mass and nearby renal parenchyma after iodine injection (17). The staging of the tumor is very essential in the management of the patients with renal neoplasms. In the studies of Foster et al and Zagoria et al revealed that the accuracy of sonography for tumor staging was $77 \%$ which was different from our study, while the reported results for the accuracy of CT scan for staging was $95 \%$ which is close to the results in our study $(18,19)$. The wide difference between in the staging results for these modalities can be probably related to kind and the updated versions of the equipment used in the examination. Since the US detection rate of tumors were similar to the dynamic CT rate, it was suggested that US was as readily applicable as dynamic CT for the diagnosis of renal parenchymal tumors, while CT scan plays an exclusive role in the staging of renal tumors. Abdominal CT represents the modality of choice for staging the primary tumor and for evaluating the possibility of locoregional and abdominal visceral metastasis (20).

\section{Conclusions:}

The US plays an important role in detection and evaluation of renal masses as an initial technique and is very accurate in distinguishing cystic from solid masses. However, Contrast-enhanced CT scan remains to be the most important technique in the detection, diagnosis, and staging of renal masses.

\section{Authors' contribution:}

Dr. Khaleel Ibraheem Mohson: supervisor and literature reviewer

Dr. Saba Qais, Nawras Khairi Fadhil: data collection, study design, manuscripts writing

\section{References:}

1. Warshauer DM, McCarthy SM, Street I, Bokbinder MJ, Glickman MG, Richter $J$ et al. Detection of renal masses: sensitivities and specificities of excretory urography/linear tomography, US and CT. Radiology .1998;169:363365

2. Bechtold RF, Zagoria RJ .Imaging approach to staging of renal cell carcinoma. Urol Clin North Am 2007;24(3):507-512

3. Gervais DA, McGovern FJ, Arellano $R S$, McDougal WS, Mueller PR. Radiofrequency ablation of renal cell Carcinoma part 1; Indications, results and role in patient management over a 6-year period and ablation of 100 tumors. AJR.2005;185(1):64-71.
4. Whittingham TA: Prog Biophys Mol Biol. 2007 Jan-Apr;93(1-3):84-110. Epub 2006 Aug 10.

5. Haliloglu AH, Gulpinar O, Ozden E, Beduk Y. Urinary ultrasonography in screening incidental renal cell carcinoma: is it obligatory? Int Urol Nephrol. 2011; 43(3):687-690.

6. Sureka B, Lal A, Khandelwal N, et al. Dynamic computed tomography and Doppler findings in different subtypes of renal cell carcinoma with their histopathological correlation. J Cancer Res Ther. 2014; 10(3):552-557.

7. Lucas Greiner, clinical abdominal sonography- benefits, potentials and limitations, medical ultrasonography, 2009, volume 11, no. 1,33-36.

8. Habboub HK, Abu-Yousef MM, Williams RD, et al. Accuracy of color Doppler sonography in assessing venous thrombus extension in renal cell carcinoma. AJR Am J Roentgenol. 1997;168:26771 .

9. Kallman DA, King BF, Hattery $R R$, et al. Renal vein and inferior vena cava tumour thrombus in renal cell carcinoma: CT, US, MRI, and venacavography. $J$ Comput Assist Tomogr 1992;16:240-7.

10. Johnson CD, Dunnick NR, Cohan RH, Illescas FF. Renal adenocarcinoma CT staging 100 tumors.AJR.2007; 148:59-63.

11. Saunders HS, Dyer RB, Shifrin RY, et al: The $C T$ nephrogram: Implications for evaluation of urinary tract disease. Radiographics 15:10691085; discussion, 1086-1088, 1995.

12. Dogra VS, Levine E: The kidney. In Haaga JR, Lanzieri CF, Gilkeson RC (eds): Computed Tomography and Magnetic Resonance Imaging of the Whole body, 4th ed. St. Louis, Mosby, 2003, pp 1537-1610.

13. Luciani LG. Renal cell carcinoma: prognostic significance of incidentally detected tumors. J Urol 2001 Apr;165(4):1223.

14. Mike M. Nguyen, Robert J. Stein, Inderbir S. Gill, Impact of Gender in Renal Cell Carcinoma: An Analysis of the SEER Database, July 2008Volume 54, Issue 1, Pages 133-142.

15. Karakiewicz PI, Jeldres C, Suardi N, etal, Age at diagnosis is a determinant factor of renal cell carcinoma- specific survival in patients treated with nephrectomy, Can Urol Assoc J. 2008 Dec; 2(6): 610-617.

16. Syed M. Nazim, M. Hammad Ather, Kamran Hafeez, Basit Salam, Accuracy of multidetector CT scans in staging of renal carcinoma, International Journal of Surgery 9 (2011) 86-90.

17. Jamis-Dow, C. A. et al. Small (< or $=3-\mathrm{cm}$ ) renal masses: detection with CT versus US and pathologic correlation. Radiology 198, 785-788 (1996).

18. Foster WL, Jr., Roberts L, Jr., Halvorsen RA, $J r$., Dunnick NR. Sonography of small renal masses with indeterminant density characteristics on computed tomography. Urologic Radiology. 1988;10(2):59-67. 
19. Zagoria RJ, Dyer RB, Wolfman NT, Hinn

$G C$, Chen YM., Radiology in the diagnosis and staging of renal cell carcinoma., Crit Rev Diagn Imaging. 1990;31(1):81-115.

20. Sheth S, Scatarige JC, Horton KM, Corl FM,

Fishman EK. Current concepts in the diagnosis and management of renal cell carcinoma: role of multidetector CT and three-dimensional CT. Radiographics. 2001;21:S237-S254.

تقييم وتحديد انتشار سرطان الكلية باستخدام فحص الموجات فوق الصوتية والمفراس الحلزوني ومقارنته بالملاحظات د. د. دليل ابراهيم محسن

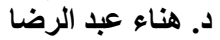

الخفية:تثخصيص ورم الكلية الخبيث وانتثارة تغير بصورة ملحوضة بعد استخام الاشعة الطبقية المحورية وبهذا يتم تثخصيص الاورام

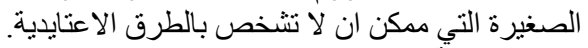

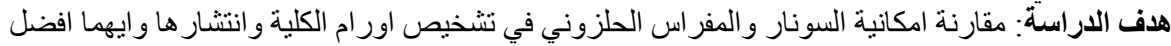

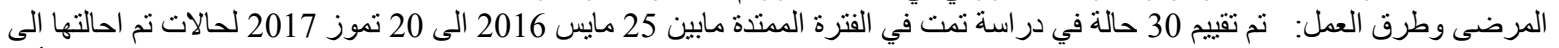

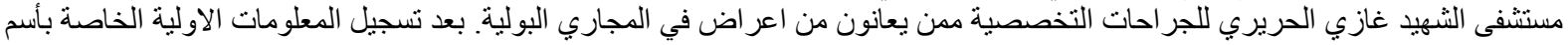

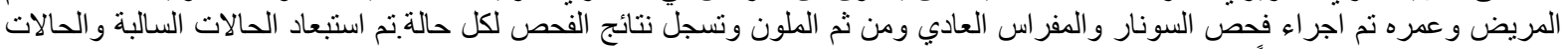

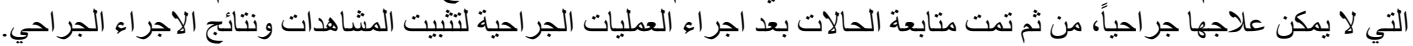

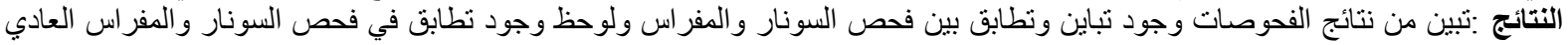

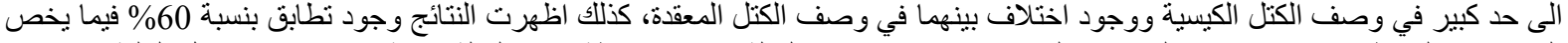

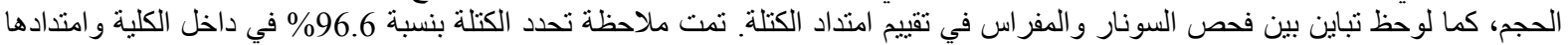

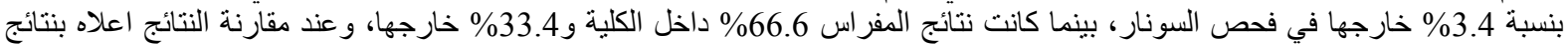

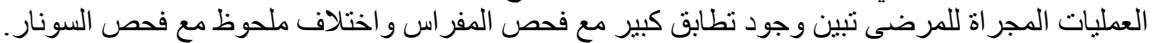

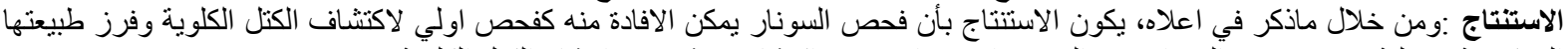

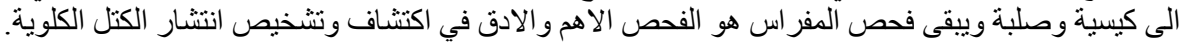
مفتاح الكلمات: المفراس الحلزوني, سونار البطن, الكتل الكلوية , سرطان الكلية. 